\title{
Modeling and Design of a Solar Rotary Dryer Bench Test for Phosphate Sludge
}

\author{
Khadija Ettahi $\mathbb{D}^{1,2}$ Meriem Chaanaoui $\mathbb{D}^{1,2}$ Vaudreuil Sébastien $\mathbb{D}^{1},{ }^{1}$ Souad Abderafi $\mathbb{D}^{2}$ \\ and Tijani Bounahmidi ${ }^{1}$ \\ ${ }^{1}$ Euromed Research Center, Euro-Mediterranean University of Fes (UEMF), Eco-Campus, Route de Meknes, Morocco \\ ${ }^{2}$ Energy Systems, Mechanical Structures and Materials, and Industrial Processes Modeling (MOSEM2PI), Université Mohammed V \\ de Rabat, Ecole Mohammadia d'Ingénieurs (EMI), Avenue Ibn Sina, BP 765 Agdal-Rabat, Morocco
}

Correspondence should be addressed to Khadija Ettahi; k.ettahi@ueuromed.org

Received 10 February 2021; Revised 14 November 2021; Accepted 21 December 2021; Published 27 January 2022

Academic Editor: Houari Ameur

Copyright ( $) 2022$ Khadija Ettahi et al. This is an open access article distributed under the Creative Commons Attribution License, which permits unrestricted use, distribution, and reproduction in any medium, provided the original work is properly cited.

\begin{abstract}
As an eco-friendlier way to manage mining waste, the use of solar energy to dry phosphate sludge in a rotary dryer is envisioned. As a first step toward this end, a design study for a bench-scale rotary dryer for phosphate sludge is detailed, using a onedimensional mathematical model developed for this task. Using the Engineering Equation Solver (EES) software, a steady-state transport phenomena model was developed that enables an estimation of the moisture and temperature profiles for both gas and product in the dryer. A sensitivity analysis evaluated the effects and influence of different geometric parameters and operating conditions on the product moisture profile. Parameters involved include the diameter of the dryer, the residence time of the product to dry, inlet air temperature, and inlet product humidity. This allowed for the selection of suitable design parameters for the operation of a phosphate sludge dryer with a $1.5 \mathrm{~m}$ length and an internal diameter of $11.5 \mathrm{~cm}$. The inlet air temperature of the rotary dryer was set at $200^{\circ} \mathrm{C}$ to achieve a reduction of moisture content in the product from $30 \%$ to $7 \%$. The model was validated through literature and experimental datasets, with an error averaging $0.22 \%$ and $1.52 \%$, respectively.
\end{abstract}

\section{Introduction}

Morocco detains the largest reserves of phosphate while being ranked as the third producer for this ore [1]. During mining activities related to phosphate beneficiation, fluorapatite is separated from the associated gangue minerals (clay, limestone, silicates ...) by a combination of various processes, including crushing and screening, washing, and/or flotation. These operations generate considerable quantities of sludge that represent more than $20 \%$ of the weight of the raw ore used for the production of phosphate concentrate [2]. In 2010, approximately 28.1 million tons of phosphate sludge were generated in Morocco only [1], and this amount is continuously increasing with the continuous progression of production. As this gangue is clayey, it is essentially a porous hygroscopic material containing a large amount of water [3]. Van Damme et al. [4] examined the characteristics and behavior of the sludge and defined it as a dense assembly of grains, saturated in liquid, with or without physicochemical interactions. This sludge is usually spread into open-air ponds, called dikes, located at the mine site. This requires large areas of urban and agricultural (arable) land, while presenting a severe problem in terms of storage capacity. Phosphate sludge can also be a source of pollution for vegetation, wildlife, air, and water [5] and present a potential global risk, particularly for villages surrounding the mining sites [6]. This by-product also has controversial long-term sustainability which may require costly rehabilitation measures at the end of the operation. One of the main challenges thus facing the phosphate industry is integrating a rational and environmentally friendly method for sludge management.

As phosphate sludge is currently considered as a mining waste without value [7], its valorization is one of the best strategies to limit its negative repercussions. A literature survey has identified ambitious possibilities for their reuse as an alternative raw material in several sectors and industries. 
Some examples include light aggregates [1], fired bricks [8, 9], cementitious binders [6], ceramic materials $[1,7]$, glass ceramics $[10,11]$, and concrete and mortars [12]. To better valorize this by-product, drying is an essential intermediate process that contributes to reducing the environmental impact and the storage and transport costs from the decreased volume and mass after water removal. Drying could also eliminate the current form of storage in landfill dikes and limit their environmental impact.

The idea behind the present work is to rely on a rotary dryer previously used for phosphate drying. As new technologies have been adopted to transport and dry phosphate, the rotary dryers are falling into disuse. This would allow their reuse to process phosphate sludge after some adaptation, with the required drying energy supplied by fossil fuels. Solar thermal energy could, however, be a possible ecofriendly alternative $[13,14]$. To the best of our knowledge, this study is the first of its kind to study the drying of phosphate washing sludge by a rotary kiln. To reach optimal parameters for an effective drying, laboratory-scale experiments are first required.

Many extensive studies on the various drying techniques exist in the literature; rotary kilns are the most common and less expensive when it comes to maintenance costs [15]. The early 60s saw the first studies on steady-state rotary dryer modeling [16]. Douglas et al. [17] improved the rotary dryer's modeling by adding the solid and gas property variations throughout the dryer. Thorne and Kelly [18] developed a dynamic model combining the particle transport model of Kelly and O'Donnell [19] with the drying kinetics model of Garside [20]. Reay [21] presented an overall model for a rotary dryer, including models for solids and equipment separately. Najim [22] developed static and dynamic models of phosphates rotary dryer. These models are based on four partial differential equations representing the mass and heat balances on the control volume of the dryer, taking into account heat and mass transfer occurring in it. Other studies have been carried out to compare the rotary dryer's mathematical models for various product flow rates and different dryer sizes [23-25]. In the case of the rotary dryer test bench design, it is more accurate to use steady-state one-dimensional modeling to reduce the calculation time and simplify the process. Rotary dryers have been applied in various industries, such as minerals, chemistry, fuel, and food. They have broad applications involving heat and mass transfer between gas and solid phases. Gunnarsson et al. [26] discussed the development of a detailed 3D radiative heat transfer model of a rotary kiln with bed material, kiln used for iron ore pelletizing. The model predicts the inner wall and bed surface temperatures with less than $11 \%$ of error. Gu et al. [15] studied numerically and experimentally the drying characteristics of wet filamentous biomass particles in a laboratory rotary kiln. The simulation results were compared to experiments under selected conditions to verify the heat and mass transfer mathematical model. Gómez-De La Cruz et al. [27, 28] studied the drying behavior of a rotary dryer used for olive oil milling waste. The results showed that the drying rate decreases when the average particle size decreases. Silvério et al. [29] compared the performances of conventional rotary dryers for fertilizer (concurrent and countercurrent flows) to a roto-aerated dryer

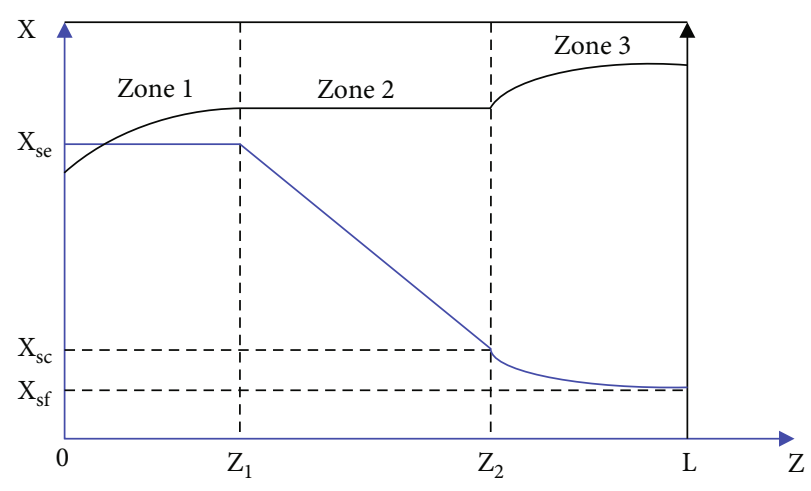

Figure 1: Profiles for solid moisture (blue line) and gas temperature (black line) in a rotary dryer [8].

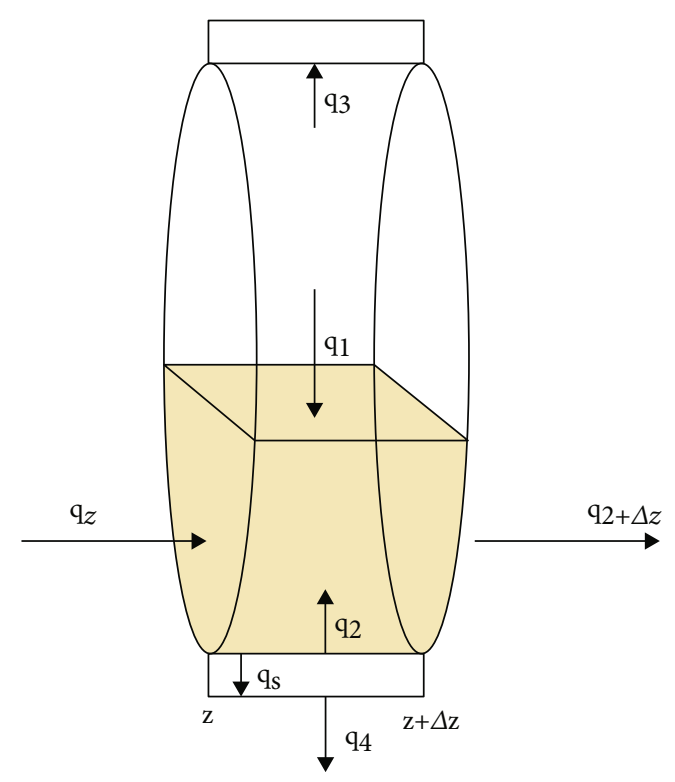

Figure 2: Control volume of rotary dryer $(\Delta z)$.

configuration, in which a hybrid distribution of mini pipes was used. The results confirm the superior performance of the hybrid roto-aerated dryer due to better gas-particle contact. Firouzi et al. [30] explored the energy consumption and rice milling quality of a drying paddy with a horizontal rotary dryer. Results were compared to those of conventional industrial batch-type bed dryer at different paddy moisture levels. Thermal energy use efficiency was estimated to be $38.8 \%$ and $26.3 \%$, respectively, at a moisture drop range of $12 \%-14.5 \%$, w. b. Kaveh et al. [31] investigated the drying kinetic, quality, energy, and exergy performance of green peas in a hot airrotary dryer using the Adaptive Neuro-Fuzzy Inference System (ANFIS) model at different temperatures and rotary rotation speeds. The drying tests were performed at three air temperature levels of 40,55 , and $70^{\circ} \mathrm{C}$ and three rotation speeds of 5 , 10 , and $15 \mathrm{rpm}$. The results showed that the energy utilization rate of the process varied in the range of $0.0121-0.1556 \mathrm{~kJ} / \mathrm{s}$. Perazzini et al. [32] developed a dynamic model of drying citrus residues in a rotary drum, with model validation carried out in a semi-industrial rotary dryer. Souza et al. [33] analyzed the 
TABLE 1: Base case for drying conditions of the bench-scale rotary dryer simulation.

\begin{tabular}{lcccc}
\hline Variable & Code & Value & Unit \\
\hline Product mass flow & $\dot{m}_{s}$ & 5 & $\mathrm{~kg} / \mathrm{h}$ \\
Solid inlet moisture & $X_{s 0}$ & 30 & $\%$ \\
Air inlet humidity & $X_{g 0}$ & 0.01 & $\mathrm{~kg}$ water $/ \mathrm{kg}$ \\
Product inlet temperature & $T_{s 0}$ & 20 & ${ }^{\circ} \mathrm{C}$ & ${ }^{\circ} \mathrm{C}$ \\
Air inlet temperature & $T_{g 0}$ & 200 & ${ }^{\circ} \mathrm{C}$ & $\mathrm{m} / \mathrm{s}$ \\
Bulb temperature & $T_{w 0}$ & 40 & $\%$ \\
Air velocity & $u$ & 0.5 & 10 & $0.5-5$ \\
Heat loss factor & $\alpha$ & $\%$
\end{tabular}

heat and mass transfer between soybean seeds and air in a nonconventional rotary dryer. A good agreement was found between simulated results and experimental data. Proch et al. [34] showed how the design of an indirectly heated rotary kiln for the pyrolysis of waste tyres could be developed based on numerical simulation results. They described a onedimensional simulation model of the particle bed's temperature and mass flow profiles, as well as for the gas phase along the axis of the indirectly heated rotary kiln. This model was successfully validated using experimental measurements.

The literature review revealed the absence of comprehensive numerical or experimental works covering phosphate sludge drying. This paper tries, therefore, to bridge existing knowledge gaps in this field. To achieve this, a steady-state one-dimensional model is developed for the design of a laboratory-scale phosphate sludge rotary dryer to evaluate the effects of drying temperature and moistures content on the dried product. Because solar energy is envisioned as the thermal energy source, modeling and sizing are done for low-temperature drying (e.g., less than $250^{\circ} \mathrm{C}$ ), using the Engineering Equation Solver (EES) software for simulations. Model validation is performed using available literature data, as well as with experimental data obtained with a bench-scale rotary dryer for phosphate sludge. Thus, this paper provides for the first time more theoretical and experimental information on the behavior of phosphate sludge during rotary drying.

\section{Model Development}

In a direct-contact rotary dryer, the dryer is continuously fed with the wet product and put in direct contact with hot gas injected in the dryer. The product is transported along the rotating cylindrical ferrule [35], with proper drying achieved through the kiln's continuous rotation. This continuous rotation has dual purposes, first in carrying the product from one end to the other, while it also serves to spread and mix particles in the hot gas stream. The phenomena related to the movement ensure the product transport from the inlet to the outlet of the ferrule, inside which hot gas is withdrawn by fans that provide a depression. Mass transfer phenomena have to be considered, where water will pass from the product to the gas stream. Heat transfer from the hot gas stream to the product to be dried ensures the phase change of phosphate-bound water into a steam state, which is then picked by the hot gas stream.

The one-dimensional model developed in this work is adapted from several literature works [36] and based on a system of equations describing mass and heat balances to consider the thermal and mass transfer between the gaseous and solid phases. It is based on the following simplifying assumptions:

(i) The dryer is considered at a steady state

(ii) The particles are considered spherical and their size uniform

(iii) No heat generation in the dryer

(iv) The product is deemed to be homogeneous

(v) The velocities of the solids and drying air along the dryer axis are constants

2.1. Governing Equations. The rotary dryer can be considered as being formed of three successive zones, as shown in Figure 1. The first zone, corresponding to the preheating stage, is aimed at heating the particles until the solid-liquid surface is equal to the equilibrium temperature. This temperature is maintained throughout the second zone while the drying rate is constant. This lasts until the critical moisture content $X_{\mathrm{sc}}$ is achieved, after which the drying rate begins to decrease and moisture content adopts an asymptotic curve that approaches the equilibrium moisture $X_{\mathrm{sf}}$ [8]. The control volume of length $\Delta z$ shown in Figure 2 is used for steady-state mass and energy balances in each zone of the rotary dryer $[37,38]$.

For the first zone, the following equations from [38] are used:

(i) For the solid:

$$
q_{1}+q_{2}=m_{s, h} C_{\mathrm{p}, \mathrm{s}} \frac{d T_{s}}{d z}
$$

(ii) For the gas: 


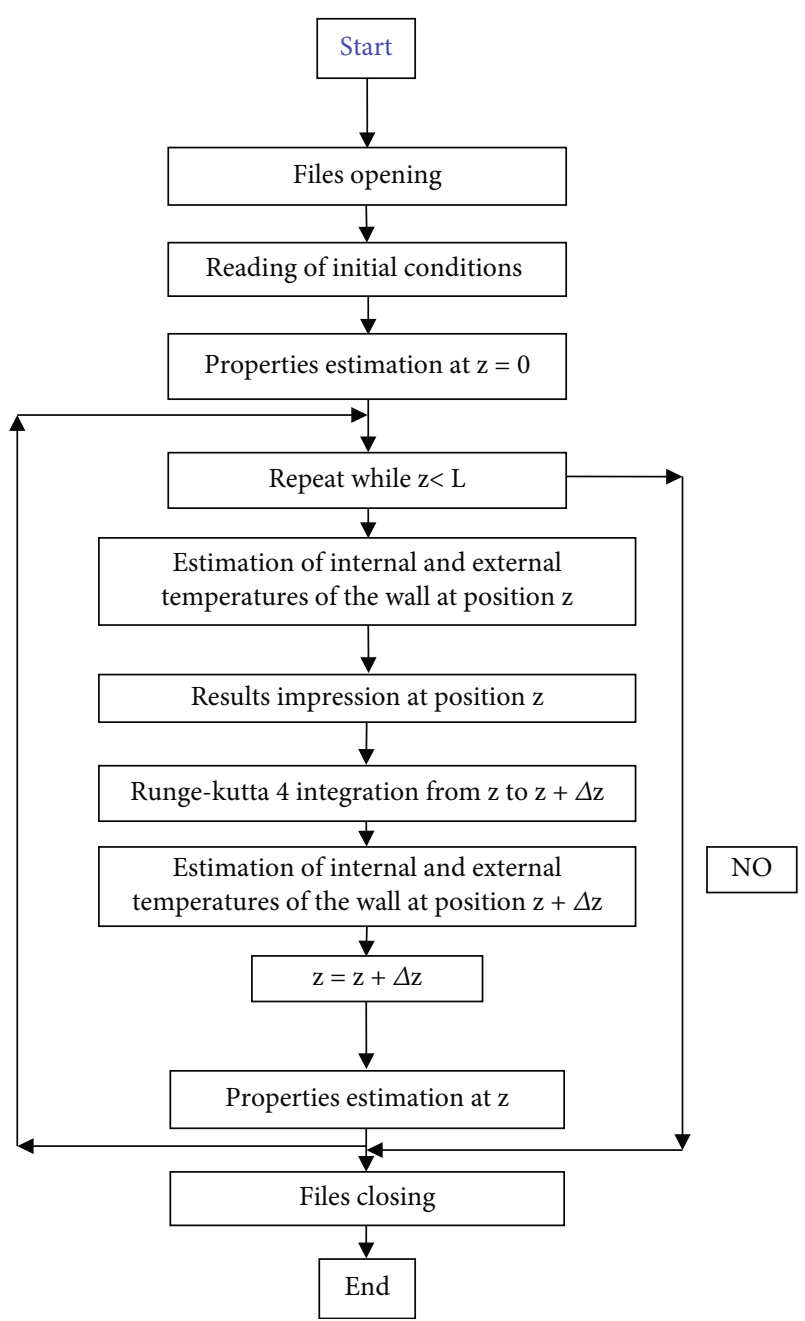

FIGURE 3: Resolution organigram.

$$
q_{1}+q_{3}=m_{g, h} C_{\mathrm{p}, \mathrm{g}} \frac{d T_{g}}{d z} .
$$

(iii) For the internal wall:

$$
q_{3}=q_{5}+q_{2}
$$

(iv) For the external wall:

$$
q_{5}=q_{4}
$$

For the second zone, the solid temperature is considered constant and the mass balance given by this equation [38]:
TABLE 2: Input parameters for model validation [41].

\begin{tabular}{lcc}
\hline Parameter & Value & Unit \\
\hline Length & 25 & $\mathrm{~m}$ \\
Internal diameter & 2.5 & $\mathrm{~m}$ \\
Rotation speed of the dryer & 10 & $\mathrm{spin} / \mathrm{min}$ \\
Inlet gas flow & 47.22 & $\mathrm{~kg} / \mathrm{s}$ \\
Inlet gas humidity & 0.01 & $\mathrm{~kg} \mathrm{water} / \mathrm{kg}$ dry air \\
Inlet gas temperature & 900 & ${ }^{\circ} \mathrm{C}$ \\
Inlet product flow & 100 & $\mathrm{~kg} / \mathrm{s}$ \\
Inlet product moisture & 16 & $\%$ \\
Inlet product temperature & 20 & ${ }^{\circ} \mathrm{C}$ \\
\hline
\end{tabular}

$$
m_{s s} \frac{d x_{s}}{d z}=-m_{g s} \frac{d x_{g}}{d z} .
$$

The energy balance is given as follows:

(i) For the gas:

$$
q_{1}+q_{3}=\frac{d\left(m_{g, h} H_{g}\right)}{d z} .
$$

(ii) For the internal wall:

$$
q_{3}=q_{5}+q_{2}
$$

(iii) For the external wall:

$$
q_{5}=q_{4}
$$

(iv) For mass transfer:

$$
q_{1}+q_{2}=f(T) \frac{d X_{s}}{d z}
$$

For the third zone, the mass balance is

$$
m_{s s} \frac{d x_{s}}{d z}=-m_{g s} \frac{d x_{g}}{d z} .
$$

The corresponding energy balance equations are obtained.

(i) For the solid: 


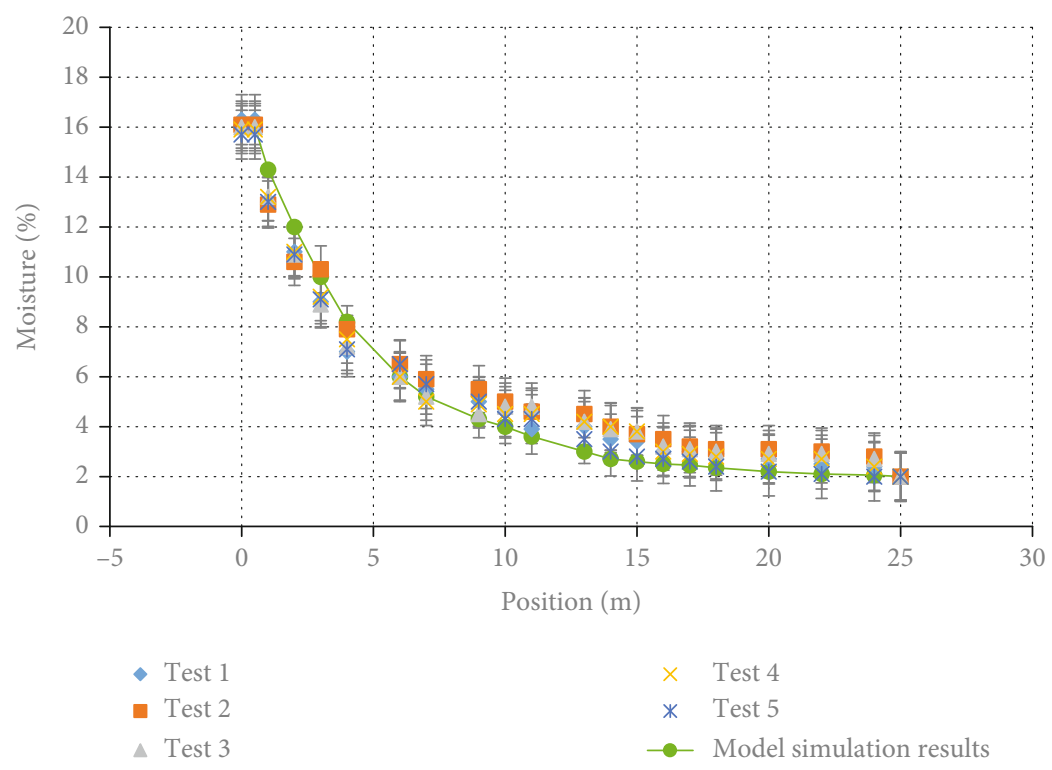

Figure 4: Moisture profile along with the dryer for the experimental and model results.

$$
q_{1}+q_{2}=\frac{d\left(m_{s, h} H_{s}\right)}{d z}
$$

(ii) For the gas:

$$
q_{1}+q_{3}=\frac{d\left(m_{g, h} H_{g}\right)}{d z} .
$$

(iii) For the internal wall:

$$
q_{3}=q_{5}+q_{2}
$$

(iv) For the external wall:

$$
q_{5}=q_{4}
$$

(v) For mass transfer:

$$
q_{1}+q_{2}=f(T) \frac{d X_{s}}{d z}
$$

with

$$
\begin{aligned}
f(T)= & m_{s, h}\left(\left(C_{p \text {,eau }}-C_{p, s}\right)\left(T-T_{\text {ref }}\right)+\lambda_{\text {eau }}\left(T_{\text {ref }}\right)\right) \\
& +m_{s, s}\left(C_{p, \text { sh }}\left(T-T_{\text {ref }}\right)+X_{s} \lambda_{\text {eau }}\left(T_{\text {ref }}\right)\right), q_{i}=h_{i} S_{i} \Delta T_{i} .
\end{aligned}
$$

The equations above constitute the one-dimensional model of the rotary dryer, describing the variables' behavior along the dryer to yield predicted profiles for product moisture and temperatures at various interfaces. Table 1 presents the inputs of the one-dimensional model, among which are the sludge and gas characteristics.

The inlet air and product temperatures used are the annual average ambient temperature in Benguerir, where testing was performed. The heat loss factor used is the maximal found in the literature to achieve a conservative error coefficient.

2.2. Parameter's Estimation. An exact expression of the heat transfer coefficients is hard to obtain since the solid is flowing inside a rotating dryer tube, requiring an extensive bibliographical study of heat transfer coefficients. It is also necessary to know the surface exchange between the various system elements to use the heat transfer coefficients better.

Heat transfer between air and product $\left(h_{1}\right)$ is given by

$$
\mathrm{Nu}_{1}=\frac{h_{1} L_{c}}{k_{\mathrm{air}}}
$$

where the Nusselt number is calculated with Ranz and Marshall's [39] correlation

$$
\mathrm{Nu}_{1}=2+0.6 \times \operatorname{Re}^{0.5} \times \operatorname{Pr}^{0.33},
$$

where Reynolds number $\operatorname{Re}=\rho D v / \mu$, Prandtl number 


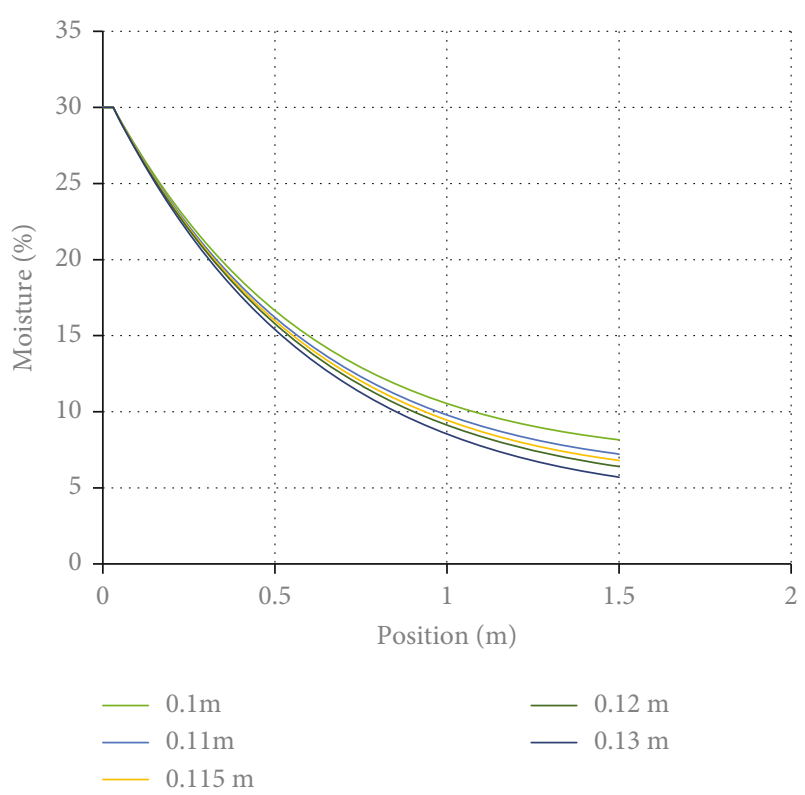

Figure 5: Moisture profiles for different diameters of the dryer.

$\operatorname{Pr}=\mu c_{p} / k_{\text {air }}, L_{c}$ is the characteristic length, and $k_{\text {air }}$ is the thermal air conductivity.

The resulting heat transfer between air and product $\left(h_{1}\right)$ can be expressed by

$$
h_{1}=\frac{\mathrm{Nu}_{1} k_{\mathrm{air}}}{S_{1}{ }^{\prime}} .
$$

The heat transfer coefficient between the product and the internal wall $\left(h_{2}\right)$ is calculated using Tscheng [21] correlation:

$$
h_{2}=11.6 \frac{k_{s}}{\theta D_{i}}\left(\frac{(N / 60) D_{i}^{2} \rho_{s} C_{p s} \theta}{120 k_{s}}\right)^{0.3} .
$$

The heat transfer coefficient between air and the internal wall $\left(h_{3}\right)$ is

$$
h_{3}=\frac{\mathrm{Nu}_{3} k_{\mathrm{air}}}{S_{3}{ }^{\prime}} .
$$

The correlation given by Agustini [6] was used to calculate the Nusselt number:

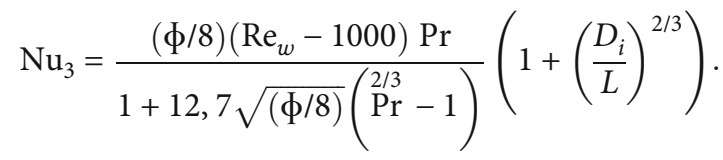

For $10 \leq L / D_{i} \leq 40$ and $\operatorname{Pr} \leq 0,5$.

And the friction factor is $\phi=\left(1,82 \log _{10} \operatorname{Re}_{w}-1.64\right)^{-2}$.

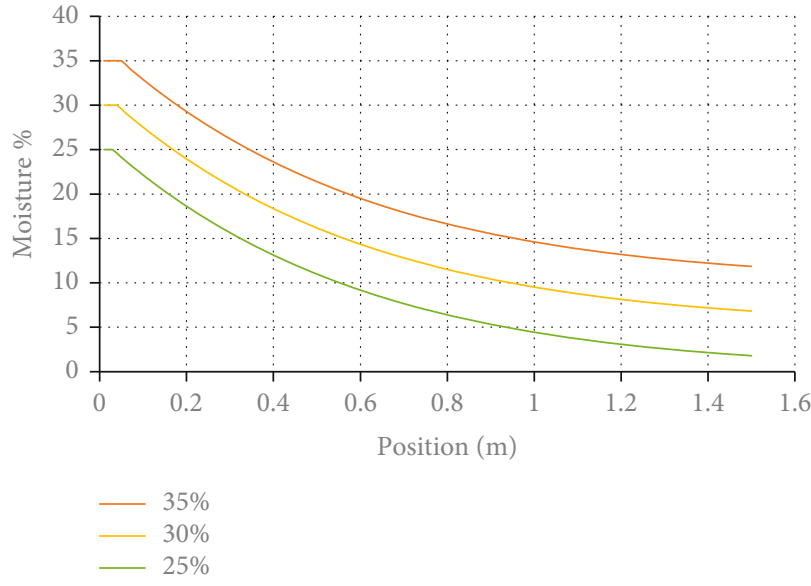

FIgURE 6: Moisture profile along with the dryer for different inlet product moistures.
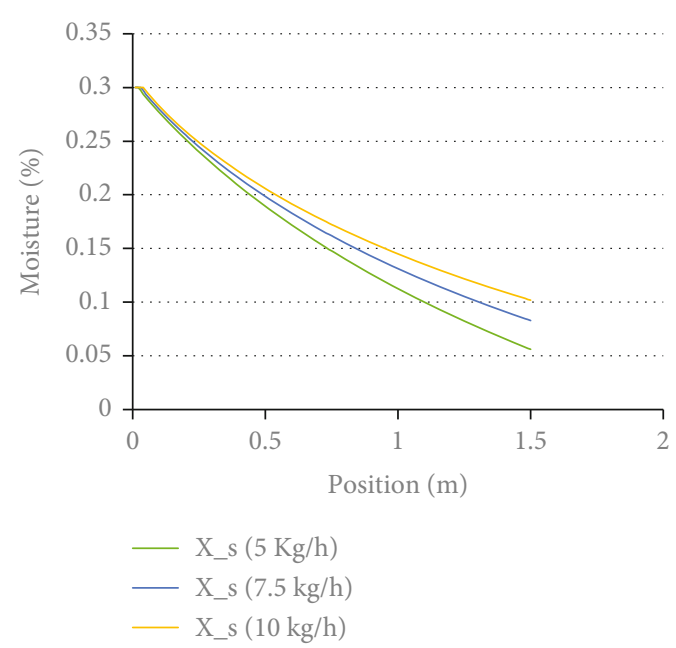

Figure 7: Moisture profile along the dryer for different product rates.

For $0.5<\operatorname{Pr}<1,5$,

$$
\mathrm{Nu}_{3}=0.0214\left(\operatorname{Re}^{0.8}-100\right) \operatorname{Pr}^{0.4}\left(1+\left(\frac{D_{i}}{L}\right)^{2 / 3}\right) .
$$

The heat exchange surface between the internal and external walls is given by Dubois [40]:

$$
S_{4}^{\prime}=\pi \frac{D_{e}-D_{i}}{\ln \left(D_{e} / D_{i}\right)} .
$$

The conduction relation served in the calculation of the heat transfer coefficient between the internal and external wall.

$$
h_{4}=2 \frac{k_{p}}{D_{e}-D_{i}} .
$$




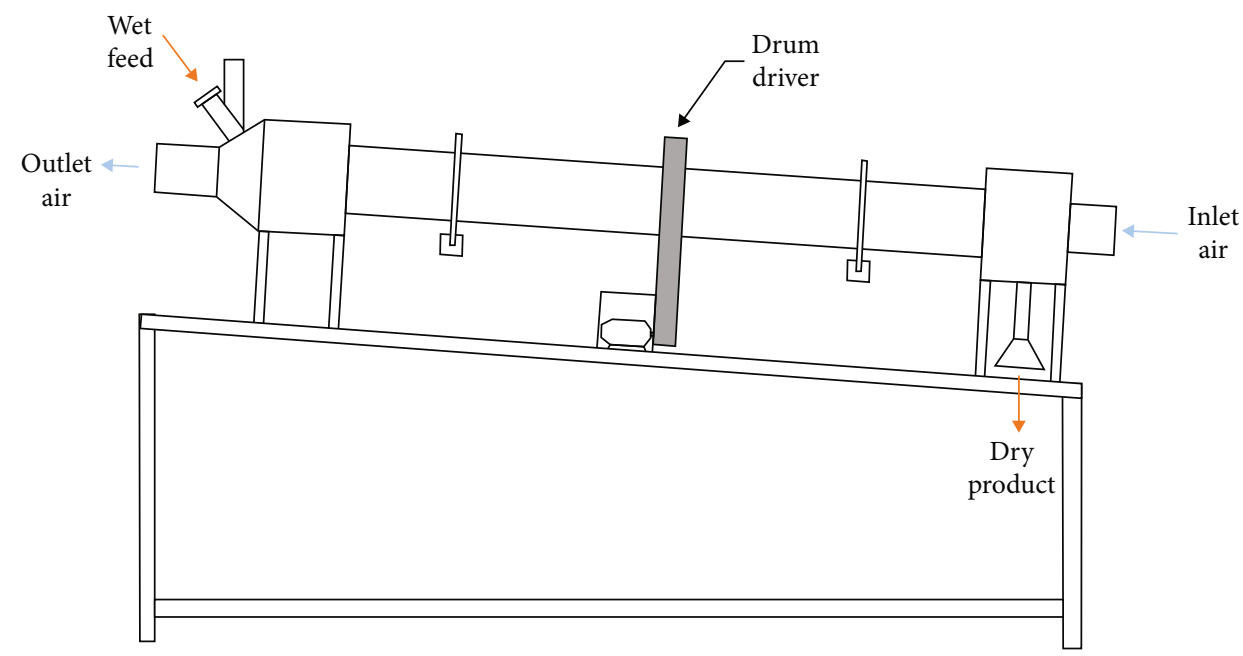

Figure 8: Drawing of the test bench.

The surface area for heat exchange between the external wall and ambient air is calculated by

$$
S_{5}^{\prime}=\pi D_{e}
$$

The heat transfer coefficient between the external wall and ambient air $\left(h_{5}\right)$ is given by Dubois [40] correlation:

$$
h_{5}=0.11\left(\frac{k_{\mathrm{air}} \operatorname{Pr}^{0.35}}{D_{e}}\right)\left(0.5 \mathrm{Re}_{w}^{2}+\mathrm{Re}^{2}+\mathrm{Gr}\right)^{0.35}
$$

Reynolds number while rotation: $\operatorname{Re}_{w}=D_{e}^{2} N / 60 \mu_{a}$. Grashof number: $\mathrm{Gr}=g \beta \Delta T L^{3} \rho_{\text {air }}{ }^{2} / \mu_{\text {air }}{ }^{2}$.

\section{Model Reliability and Resolution}

3.1. Resolution Organigram. Equations of the model were solved using the Runge Kutta fourth-order method with variable integration step value programmed in EES software. Simulation results show the profiles of moisture content for both air and product as well as the temperature of air and product along the dryer. For each control volume, the properties of air and solid are calculated and the equations solved. The organigram used to resolve the calculations is shown in Figure 3, highlighting the iterations and conditions used. The estimated properties and initial conditions are listed in Table 1.

3.2. Model Validation. To validate the model, a comparison with the work of Raffak et al. [41] has been made. Raffak et al. [41] have worked on the simulation and experimentation of a $25 \mathrm{~m}$ long industrial phosphate rotary dryer with an internal diameter of 2.5 meters. Various parameters governing the operation of these dryers were measured during this work. Among those parameters are the conditions of the hot gases (flow rate, temperature, water content, and composition) and the product (water content, feed rate, particle size, and specific heats), the ambient temperature of the dedusting chamber, the temperature of chimney gases, of the bricks, and at the outlet of the hearth (the nozzle), the flow rate of fuel oil, and the depression at the nozzle as well as the primary, secondary, and parasitic airflow rates. These inputs have been used to validate our model through a comparison with Raffak et al.'s experimental results of moisture profiles. Table 2 lists the input parameters used.

A comparison between the simulation results (curve) and Raffak et al.'s [41] experimental values of product moisture along the dryer is found in Figure 4. The five tests were taken in similar conditions with an inlet product moisture of $16 \%$ (precisely $16.3 \%, 16.1 \%, 16 \%, 15.9 \%$, and $15.7 \%$ ). The model simulated the same experimental conditions, with an inlet product moisture of $16 \%$. Figure 4 shows that simulation results follow a similar trend to the experimental data at the various dryer positions. The error was calculated between each series of experiments and between the models, averaging $0.22 \%$ while not exceeding $1.5 \%$ at worst. We can conclude that the developed model accurately predicts the rotary dryer's behavior.

This comparison proved the model's validity for conditions listed in Table 2. To evaluate the model's accuracy for different assumptions, it is required to perform a sensitivity analysis for a bench test scale rotary dryer before choosing the optimal size allowing work on phosphate sludge.

\section{Sensitivity Analysis and Design}

Although several variables are involved in a rotary dryer design, certain rules must be followed to ensure that the design is consistent with the operating conditions. Simulations were performed for a $1.5 \mathrm{~m}$ long dryer of $11.5 \mathrm{~cm}$ diameter to calculate the solid moisture and gas temperature at the outlet of the dryer. Results show the product's moisture and air temperature along the dryer for an inlet air temperature of $200^{\circ} \mathrm{C}$. Through a sensitivity analysis of the dryer diameter, product inlet moisture, and feed rate, the influence of these parameters on the simulated final moisture content was evaluated. This allows the rotary dryer design to achieve target conditions. 
TABLE 3: Design parameters of the bench-scale rotary dryer.

\begin{tabular}{|c|c|c|c|}
\hline Results of process design calculations & Code & Value & Unit \\
\hline Internal diameter of the dryer & $D_{i}$ & 11.5 & $\mathrm{~cm}$ \\
\hline Length of the dryer & $L$ & 1.5 & $\mathrm{~m}$ \\
\hline Air inlet temperature & $T_{g 0}$ & 100 & ${ }^{\circ} \mathrm{C}$ \\
\hline Air inlet humidity & $X_{g 0}$ & 27.25 & $\mathrm{~kg}$ water $/ \mathrm{kg}$ \\
\hline Air inlet flow & $\dot{m}_{g}$ & 27.25 & $\mathrm{~kg} / \mathrm{h}$ \\
\hline Air mass velocity & G & 3975.55 & $\mathrm{~kg} / \mathrm{m}^{2} \cdot \mathrm{s}$ \\
\hline Air outlet temperature & $T_{g f}$ & 86.85 & ${ }^{\circ} \mathrm{C}$ \\
\hline Air outlet humidity & $X_{g f}$ & 0.0558 & \\
\hline Product outlet temperature & $T_{s f}$ & 76.85 & ${ }^{\circ} \mathrm{C}$ \\
\hline Product outlet humidity & $X_{s f}$ & 6 & $\%$ \\
\hline Evaporated mass & $m_{v}$ & 1.25 & $\mathrm{~kg} / \mathrm{h}$ \\
\hline Coefficient of heat transfer & $U_{a}$ & 1635.36 & $\mathrm{~kJ} / \mathrm{h} \cdot \mathrm{K} \cdot \mathrm{m}^{3}$ \\
\hline Logarithmic average of the temperature & $\Delta T_{m}$ & 108.76 & ${ }^{\circ} \mathrm{C}$ \\
\hline Overall heat consumption & $Q_{t}$ & 4730.05 & $\mathrm{~kJ} / \mathrm{h}$ \\
\hline
\end{tabular}

4.1. Effect of Dryer Diameter on the Final Moisture Content. The length-diameter $\left(L / D_{i}\right)$ ratio can vary between a value of 2 in the case of large dryers to 20 for long thin dryers [5]. Variation of the internal diameter is performed while keeping this ratio between 11.54 and 15, yielding an internal diameter varying between 10 and $13 \mathrm{~cm}$. Simulations were performed with a process inlet air temperature of $200^{\circ} \mathrm{C}$ and a feed rate of $5 \mathrm{~kg} / \mathrm{h}$ of wet phosphate sludge $30 \%$ humidity, $20^{\circ} \mathrm{C}$ ). Figure 5 shows that increasing the dryer diameter results in a decrease in product's moisture, all other parameters being identical. This can be explained by the increased exchange surface between air and product. A constant humidity level can be observed for the initial length, which corresponds to the preheating phase before the product reaches the evaporation temperature. The target moisture for the simulations was fixed at $7 \%$, closely achieved for a diameter of $11.5 \mathrm{~cm}$.

4.2. Effect of Product Inlet Moisture on Its Final Moisture Content. The moisture content for the solid at inlet affects the drying results, as shown by Figure 6 . Using an $11.5 \mathrm{~cm}$ internal diameter dryer with an inlet air temperature of $200^{\circ} \mathrm{C}$, an increased dryer length is required to achieve a $7 \%$ final moisture content when the initial moisture content is higher. This highlights the benefits of reducing the solid's inlet moisture content as much as possible to limit the dryer's length.

\subsection{Effect of Product Feed Rate on Its Final Moisture Content.} The impact of product feed rate on its moisture content along the dryer length is shown in Figure 7. The drying model was solved for three different feed rates, namely, 5, 7.5, and $10 \mathrm{~kg} / \mathrm{h}$, having an initial $30 \%$ moisture content. Drying conditions were set at $200^{\circ} \mathrm{C}$ for the inlet temperature, a $3.5 \mathrm{~m} / \mathrm{s}$ air velocity, and an $11.5 \mathrm{~cm}$ internal diameter for the dryer. The resulting outlet moisture shows an increase with feed rate,

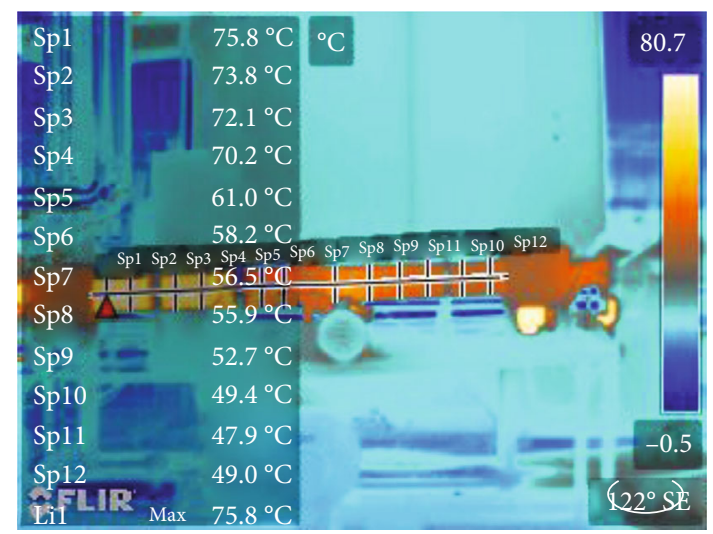

FIgURE 9: Temperature distribution in the dryer measured with the FLIR T440 camera on April 24, 2019.

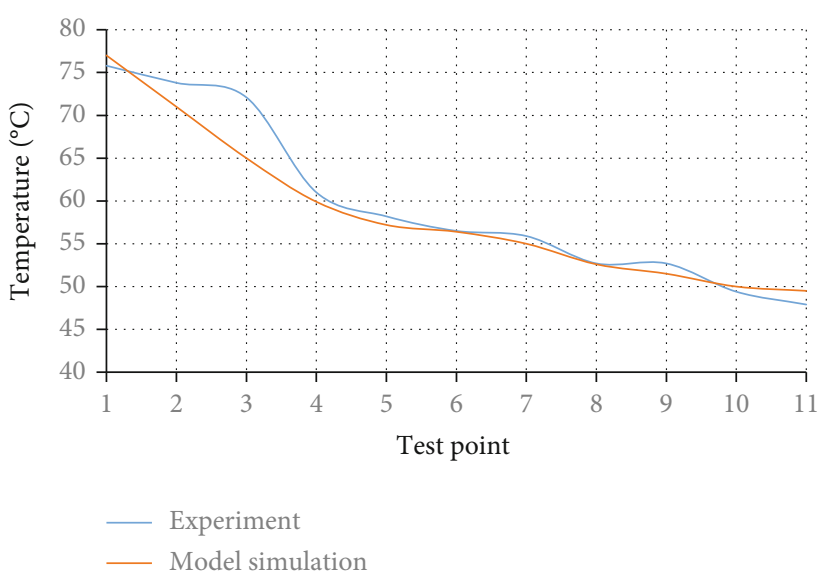

Figure 10: Temperature profile of the external wall. 
with moisture values of $6 \%, 8 \%$, and $10 \%$, respectively, derived from the $5,7.5$, and $10 \mathrm{~kg} / \mathrm{h}$ feed rate. The targeted outlet moisture of $7 \%$ is thus achieved for a $5 \mathrm{~kg} / \mathrm{h}$ feed rate, with higher feed rate leading to moisture values exceeding this threshold.

\section{Dryer Choice and Experiment}

Relying on the sensitivity analysis, a laboratory-scale rotary dryer has been procured to carry out the experiments. This rotary dryer has a $1.5 \mathrm{~m}$ long tube with an internal diameter of $11.5 \mathrm{~cm}$. Figure 8 represents the schematic drawing of this rotary dryer.

The developed model was used to calculate the different operating parameters of this lab-scale rotary dryer to achieve the targeted humidity content for the product (Table 3 ).

An indirect way to validate the heat transfer components of the model is through the external wall temperature of the dryer. Using a thermal camera (FLIR T440), the temperature of the external dryer wall along its length was measured for comparison to simulation. Multiple inlet air temperatures were used during testing with the lab-scale dryer. Figure 9 shows thermal imaging of the operating dryer during testing in solar mode, where the inlet air temperature was $100^{\circ} \mathrm{C}$. To achieve solar heating of the inlet air, the rotary dryer was coupled to a parabolic trough [13] system via a finned tube heat exchanger designed $[14,42]$ for this solar application.

A comparison of the external wall temperature between model predictions and experimental results was made (Figure 10). The dryer was, in this case, operated in solar mode, explaining the lower temperature of $100^{\circ} \mathrm{C}$ for the inlet air. It can be seen that the temperature profiles coincide in several points, with a difference of less than $2 \%$ found in many locations. Variations in product repartition inside the dryer can explain these differences, with some zones less charged with the product, which will affect the heat transfer between air and product, creating hot spots on the external wall. After a validation based on the literature, the model is reliable at the laboratory scale with an average error of $1.52 \%$.

\section{Conclusion}

Phosphate sludge has always been environmentally problematic, and more durable solutions are required to manage such industrial wastes. Their valorization through utilization in other industries would create value, but this requires a drying step that could be performed in this case on disused rotary dryers. As phosphate sludge drying has never been characterized for a rotary dryer, testing at a laboratory scale is required beforehand.

A one-dimensional mathematical model for phosphate sludge drying was thus developed before being used to design a laboratory-scale rotary dryer. Model validation was performed by comparing test results obtained from literature, achieving a low error value. Next, a sensitivity analysis was performed on multiple design and operation parameters to identify the best design approach. From this, the best drying conditions were identified to achieve the targeted moisture content in the phosphate sludge at the outlet. Finally, an indi- rect experimental validation of the model was realized by comparing the simulated external wall temperature profile with thermal imagery results obtained for a rotary dryer operating in the same conditions. The model developed in this work can serve as the basis for the design of an upscaled rotary dryer for phosphate sludge.

\section{Nomenclature}

$Q_{t}: \quad \quad \quad$ Volumetric heat transferred $(\mathrm{J} / \mathrm{s})$

$U_{a}$ : Coefficient of volumetric heat transferred (J/ $\left.\left(\mathrm{s} \cdot \mathrm{m}^{3} \cdot \mathrm{K}\right)\right)$

$V_{v}: \quad$ The volume of the dryer $\left(\mathrm{m}^{3}\right)$

$(\Delta T)_{m}: \quad$ The logarithmic mean temperature difference between the air and the solids at the inlet and outlet of the dryer $(\mathrm{K})$

G: $\quad$ Air mass velocity $\left(\mathrm{kg} / \mathrm{s} \cdot \mathrm{m}^{2}\right)$

$D: \quad$ Diameter of the dryer $(\mathrm{m})$

$m_{g, h}, m_{g, s}$ : Rate of flow of the humid air and dry air, respectively $(\mathrm{kg} / \mathrm{h})$

$m_{s, h}, m_{s, s}$ : Rate of flow of the humid product and dry product, respectively $(\mathrm{kg} / \mathrm{h})$

$H_{s}: \quad$ The enthalpy of the product $(\mathrm{J} / \mathrm{kg})$

$H_{g}$ : The enthalpy of gas $(\mathrm{J} / \mathrm{kg})$

$z: \quad$ The position along with the rotary dryer $(\mathrm{m})$

$C_{p, i}: \quad$ Heat capacity of the element $i(\mathrm{~J} / \mathrm{kg} / \mathrm{K})$

$S_{j}^{\prime}: \quad$ Exchange surface $(\mathrm{m})$

$q_{1}$ : $\quad$ Convection between the air and the surface of the solid $(\mathrm{W} / \mathrm{m} \cdot \mathrm{K})$

$q_{2}$ : Conduction through the internal wall of the bench $(\mathrm{W} / \mathrm{m} \cdot \mathrm{K})$

$q_{3}$ : $\quad$ Convection between the air and the surface of the internal wall $(\mathrm{W} / \mathrm{m} \cdot \mathrm{K})$

$q_{4}: \quad$ Conduction through the wall $(\mathrm{W} / \mathrm{m} \cdot \mathrm{K})$

$q_{5}$ : Convection between the ambient air and the surface of the external wall $(\mathrm{W} / \mathrm{m} \cdot \mathrm{K})$

$\lambda_{w}: \quad\left(\mathrm{W} \cdot \mathrm{m}^{2} \mathrm{~K}\right)$

$L: \quad$ Length of the dryer $(\mathrm{m})$

$D_{i}: \quad$ Internal diameter of the dryer $(\mathrm{m})$

$D_{e}: \quad$ External diameter of the dryer $(\mathrm{m})$

$\beta: \quad$ Dilatation coefficient

$\mu_{\text {air }}: \quad$ Air viscosity $(\mathrm{kg} / \mathrm{m} \cdot \mathrm{s})$

$k_{i}$ : Conduction coefficient of the element $i$ (W/ $\mathrm{m} \cdot \mathrm{K})$.

\section{Data Availability}

The data used to support the findings of this study are included within the article.

\section{Conflicts of Interest}

The authors declare that they have no conflicts of interest.

\section{Acknowledgments}

The authors would like to thank IRESEN (Institut de Recherche en Energie Solaire et Energies Nouvelles) for their continuing financial support. 


\section{References}

[1] M. Loutou, M. Hajjaji, M. Mansori, C. Favotto, and R. Hakkou, "Phosphate sludge: thermal transformation and use as lightweight aggregate material," Journal of Environmental Management, vol. 130, pp. 354-360, 2013.

[2] M. Ettoumi, M. Jouini, C. M. Neculita et al., "Characterization of Kef Shfeir phosphate sludge (Gafsa, Tunisia) and optimization of its dewatering," Journal of Environmental Management, vol. 254, 2020.

[3] M. Milhé, C. Charlou, M. Sauceau, and P. Arlabosse, "Modeling of sewage sludge flow in a continuous paddle dryer," Drying Technology, vol. 33, no. 9, pp. 1061-1067, 2015.

[4] H. Van Damme, S. Mansoutre, P. Colombet, C. Lesaffre, and D. Picart, "Les pates : des milieux granulaires lubrifies et cohesifs," Comptes Rendus Physique, vol. 3, no. 2, pp. 229-238, 2002.

[5] A. A. Negm and A. Z. M. Abouzeid, "Utilization of solid wastes from phosphate processing plants," Physicochemical Problems of Mineral Processing, vol. 42, pp. 5-16, 2008.

[6] Q. Chen, Q. Zhang, A. Fourie, and C. Xin, "Utilization of phosphogypsum and phosphate tailings for cemented paste backfill," Journal of Environmental Management, vol. 201, pp. 19-27, 2017.

[7] R. Hakkou, M. Benzaazoua, and B. Bussière, "Valorization of phosphate waste rocks and sludge from the Moroccan phosphate mines: challenges and perspectives," Procedia Engineering, vol. 138, pp. 110-118, 2016.

[8] M. Loutou, Y. Taha, M. Benzaazoua, Y. Daafi, and R. Hakkou, "Valorization of clay by-product from Moroccan phosphate mines for the production of fired bricks," Journal of Cleaner Production, vol. 229, pp. 169-179, 2019.

[9] Y. Taha, M. Benzaazoua, R. Hakkou, and M. Mansori, "Coal mine wastes recycling for coal recovery and eco-friendly bricks production," Minerals Engineering, vol. 107, pp. 123-138, 2017.

[10] L. Li, F. Wang, Q. Liao, Y. Wang, H. Zhu, and Y. Zhu, "Synthesis of phosphate based glass-ceramic waste forms by a meltquenching process: the formation process," Journal of Nuclear Materials, vol. 528, 2020.

[11] Y. Yang, Z. Wei, Y. L. Chen, Y. Li, and X. Li, "Utilizing phosphate mine tailings to produce ceramisite," Construction and Building Materials, vol. 155, pp. 1081-1090, 2017.

[12] R. Argane, M. Benzaazoua, R. Hakkou, and A. Bouamrane, "Reuse of base-metal tailings as aggregates for rendering mortars: assessment of immobilization performances and environmental behavior," Construction and Building Materials, vol. 96, pp. 296-306, 2015.

[13] M. Chaanaoui, S. Abderafi, S. Vaudreuil, and T. Bounahmidi, "Prototype of phosphate sludge rotary dryer coupled to a parabolic trough collector solar loop: integration and experimental analysis," Solar Energy, vol. 216, pp. 365-376, 2021.

[14] M. Chaanaoui, K. Ettahi, S. Abderafi, S. Vaudreuil, and T. Bounahmidi, "Comparative analysis between optimum configurations of finned tube heat exchanger: application for solar drying," Case Studies in Thermal Engineering, vol. 22, 2020.

[15] C. Gu, Z. Yuan, S. Sun, L. Guan, and K. Wu, "Simulation investigation of drying characteristics of wet filamentous biomass particles in a rotary kiln," Fuel Processing Technology, vol. 178, pp. 344-352, 2018.

[16] C. Scientific and N. S. Wales, "An analysis moisture of transient flow of heat and beds during," International Journal of Heat and Mass Transfer, vol. 11, pp. 675-687, 1968.
[17] P. L. Douglas, A. Kwade, P. L. Lee, and S. K. Mallick, "Simulation of a rotary dryer for sugar crystalline," Drying Technology, vol. 11, no. 1, pp. 129-155, 1993.

[18] B. Thorne and J. J. Kelly, "Mathematical modelling of rotary dryers," in International symposium on solid separation processes, Proc.Drying'80, pp. 160-169, Washington, USA, 1980.

[19] J. J. Kelly and P. O'Donnell, "Residence time model for rotary drums," Transactions of the Institution of Chemical Engineers, vol. 55, no. 4, 1977.

[20] J. Garside, L. W. Lord, and R. Reagan, “The drying of granular fertilizers," Chemical Engineering Science, vol. 25, no. 7, pp. 1133-1148, 1970.

[21] D. Reay, "Theory in the design of dryers," Chemical Engineer, no. 346, pp. 501-506, 1979.

[22] K. Najim, "Modelling and learning control of rotary phosphate dryer," International journal of systems science, vol. 20, no. 9, pp. 1627-1636, 1989.

[23] F. Castaño, F. R. Rubio, and M. G. Ortega, "Modeling of a cocurrent rotary dryer," Drying Technology, vol. 30, no. 8, pp. 839-849, 2012.

[24] Q. Xu and S. Pang, "Mathematical modeling of rotary drying of woody biomass," Drying Technology, vol. 26, no. 11, pp. 1344-1350, 2008.

[25] H. Abbasfard, H. H. Rafsanjani, S. Ghader, and M. Ghanbari, "Mathematical modeling and simulation of an industrial rotary dryer: a case study of ammonium nitrate plant," Powder Technology, vol. 239, pp. 499-505, 2013.

[26] A. Gunnarsson, K. Andersson, B. R. Adams, and C. Fredriksson, "Full-scale 3D-modelling of the radiative heat transfer in rotary kilns with a present bed material," International Journal of Heat and Mass Transfer, vol. 147, 2020.

[27] F. J. Gómez-De La Cruz, P. J. Casanova-Peláez, J. M. PalomarCarnicero, and F. Cruz-Peragón, "Modeling of olive-oil mill waste rotary dryers: green energy recovery systems," Applied Thermal Engineering, vol. 80, pp. 362-373, 2015.

[28] F. J. Gómez-de la Cruz, P. J. Casanova-Peláez, J. M. PalomarCarnicero, and F. Cruz-Peragón, "Characterization and analysis of the drying real process in an industrial olive-oil mill waste rotary dryer: a case of study in Andalusia," Applied Thermal Engineering, vol. 116, pp. 1-10, 2017.

[29] B. C. Silvério, E. B. Arruda, C. R. Duarte, and M. A. S. Barrozo, "A novel rotary dryer for drying fertilizer: comparison of performance with conventional configurations," Powder Technology, vol. 270, pp. 135-140, 2015.

[30] S. Firouzi, M. R. Alizadeh, and D. Haghtalab, "Energy consumption and rice milling quality upon drying paddy with a newly-designed horizontal rotary dryer," Energy, vol. 119, pp. 629-636, 2017.

[31] M. Kaveh, Y. Abbaspour-Gilandeh, and G. Chen, "Drying kinetic, quality, energy and exergy performance of hot airrotary drum drying of green peas using adaptive neuro-fuzzy inference system," Food and Bioproducts Processing, vol. 124, pp. 168-183, 2020.

[32] H. Perazzini, M. T. B. Perazzini, F. B. Freire, F. B. Freire, and J. T. Freire, "Modeling and cost analysis of drying of citrus residues as biomass in rotary dryer for bioenergy," Renewable Energy, vol. 175, pp. 167-178, 2021.

[33] G. F. M. V. Souza, P. S. Avendaño, M. C. C. Francisquetti, F. R. C. Ferreira, C. R. Duarte, and M. A. S. Barrozo, "Modeling of heat and mass transfer in a non-conventional rotary dryer," Applied Thermal Engineering, vol. 182, 2021. 
[34] F. Proch, K. Bauerbach, and P. Grammenoudis, “Development of an up-scalable rotary kiln design for the pyrolysis of waste tyres," Chemical Engineering Science, vol. 238, 2021.

[35] A. Boulemtafes and D. Semmar, "Conception et réalisation d' un séchoir solaire indirect," Revue des Energies Renouvelables: Valorisation, vol. 62, pp. 97-100, 1999.

[36] S. H. Tscheng and A. P. Watkinson, "Convective heat transfer in a rotary kiln," Canadian Journal of Chemical Engineering, vol. 57, no. 4, pp. 433-443, 1979.

[37] S. S. Agustini, "Regenerative action of the wall on the heat transfer for directly and indirectly heated rotary kilns," Doctoral Thesis, pp. 1-148, 2006.

[38] A. Mujumdar and W. Zhonghua, "Thermal drying technologies - cost-effective innovation aided by mathematical modeling approach,” Drying Technology, vol. 26, 2007.

[39] W. Ranz, "Evaporation from drops 1," Chemical Engineering Progress, vol. 48, no. 3, pp. 141-146, 1952.

[40] M. Dubois, Modélisation Mathématique d'un Four Rotatif de Calcination d'Alumine, Université du Québec à Chicoutimi, Mémoire de maîtrise, 1996.

[41] T. Raffak, M. Agouzoul, E. M. Mabsate, A. Chik, and A. Alouani, "Etude expérimentale d'un four rotatif de séchage des phosphates," Revue des Energies Renouvelables, pp. 249254, SMSTS'08 Alger, 2008.

[42] M. Chaanaoui, K. Ettahi, S. Vaudreuil, and T. Bounahmidi, “A finned tube heat exchanger coupled to parabolic trough solar collector for drying application," AIP Conference Proceedings, vol. 2126, 2019. 